\title{
ORTHODONTIC RETENTION BY PERIO ESTHETIC PROCEDURES- AN OVERVIEW
}

Dr. Ramya Rajendran, Dr. C. Burnice Nalina Kumari*, Dr.Padmalochani**, Dhwani.K.Dedhia*, Dr.Shalini Arumugam*, Dr.Vijayalakshmi.R*

Department of Orthodontics, Adhiparasakthi Dental College and Hospital, Melmaruvathur, Kanchipuram, Tamilnadu, India

*Department of Periodontology, Meenakshi Ammal Dental College, Chennai, Tamilnadu, India **Private Practice, Dubai.

\section{To access $\&$ cite this article}

Website: jidam.idamadras.com

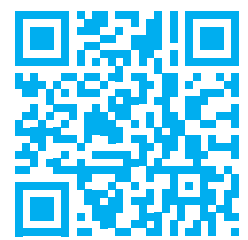

DOI:10.37841/jidam_2020_V7_I3_04

\section{Address for Correspondence:}

Dr. Ramya Rajendran, MDS.,

Reader, Department of Orthodontics and

Dentofacial Orthopaedics,

Adhiparasakthi Dental College and Hospital,

Melmaruvathur, Kanchipuram-603319.

Email: ramyaraj2884@yahoo.co.in

\section{ABSTRACT}

Esthetics has become a great concern to attain a perfect smile and it has given greater importance for dental treatment. The periodontal tissues react to orthodontic forces. The link between Orthodontics and Periodontics has become more evident for tooth movement to occur. In recent days, due to more number of adult patients seeking orthodontic treatment, the Orthodontist frequently face patients with complaints of post-orthodontic retentive esthetic measures of periodontium. Esthetic considerations such as midline diastema, uneven gingival margins, crown lengthening or other functional problems related to periodontium is advised in orthodontic treatment planning. The purpose of this review is to provide an optimized treatment outcome in relation to periodontium during orthodontic correction.

KEYWORDS: Perio esthetics, Gingival Augmentation, Orthodontic Retention

\footnotetext{
Received : :06.09.2020

Accepted : : 15.09.2020

Published : :27.09.2020
} 


\section{INTRODUCTION:}

Esthetics has become one of the greatest concern in the present day that gives increased importance to look for dental treatment, for obtaining a perfect smile. Some particular areas evaluated are like, how the periodontal tissues respond to the orthodontic forces, effect of tooth movement on the periodontium, reaction of circumferential supracrestal fiberotomy to prevent orthodontic relapse, mucogingival alterations and time relationship which occur during orthodontic tooth movement and periodontal treatment. In addition to this, esthetic problem is also caused by midline diastema and aberrant frenum which presents a compromise in orthodontic treatment and may lead to recurrence after treatment.

\section{FRENECTOMY:}

Diastema is the presence of space more than $0.5 \mathrm{~mm}$ in adult maxillary central incisors. This condition has often posed an esthetic problem. The most important etiological factor for midline diastema is the presence of aberrant frenum ${ }^{1}$

\section{CLASSIFICATION:}

- The labial frenal attachments have been classified as mucosal, gingival, papillary and papilla penetrating, by Placek et al (1974) ${ }^{2}$.

- Mucosal-when the frenal fibers are attached upto the mucogingival junction.

- Gingival - when the fibers are inserted within the attached gingiva.

- Papillary - when the fibers are extending into the interdental papilla.

- Papilla penetrating - when the frenal fibers cross the alveolar process and extend upto the palatine papilla.

\section{INDICATIONS FOR FRENUM REMOVAL:}

- The frenum is distinguished as pathogenic and it is indicated for removal when:

- A maxillary midline diastema may be caused by the attachment of labial frenum into the notch in the alveolar bone so that the band of heavy fibrous tissue lies between the central incisors.

- An inferiorly attached frenum in the gingival margin has low, thick and fleshy frenal attachment which causes gingival recession and potential obstruction for maintaining good oral hygiene.

- An aberrant frenum is often associated with an inadequate attached gingiva and a shallow vestibule.

- Depending upon the extent and severity of the tissue growth, the correction of high frenal attachment can be done before or after orthodontic procedures. There are number of methods to assess the involvement of frenum in the etiology of midline diastema such as : 1)direct visualization 2) blanching of tissue on lifting the upper lip (Tension test) 3) notch or triangular shaped intermaxillary segment on radiographic examination.

- There is excess tissue growth in some cases which may require additional corrective procedure before and after space closure.

- In most orthodontic midline diastema cases, it is preferable to delay the procedures regarding the frenum until the orthodontic space closure is completed. After the space closure completion, if the frenectomy is done, the scar tissue contraction phenomenon takes place which will lead to prevention of relapse. This procedure is done only in the permanent dentition by following eruption of maxillary canines.

\section{TREATMENT:}

Normally the aberrant frenum can be treated by frenectomy or frenotomy. Frenectomy is the complete removal of frenum including its attachment to bone. Frenotomy is to create a zone of attached gingiva between the gingival margin and the frenum by giving an incision and relocating the frenum ${ }^{2}$. Frenectomy can be skilled by three techniques. They are:

- Routine scalpel technique

- Electrocautery ${ }^{3}$ and

- By using lasers 4

By using a scalpel, the routine scalpel technique has been carried out in the conventional method which involves excision of frenum. But this conventional method results in a regular postoperative complications (Fig 1, Fig 2 and Fig 3). 


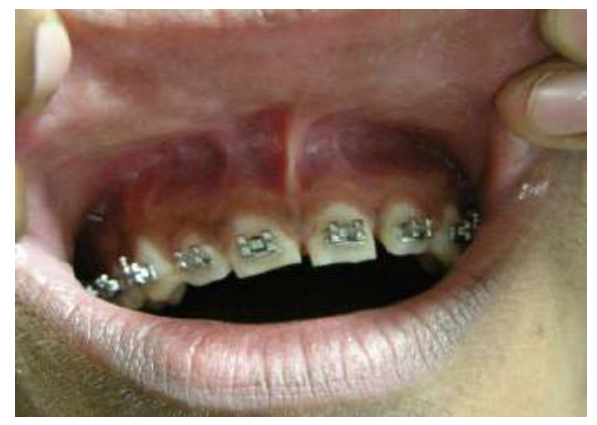

Fig 1: Pre-operative view

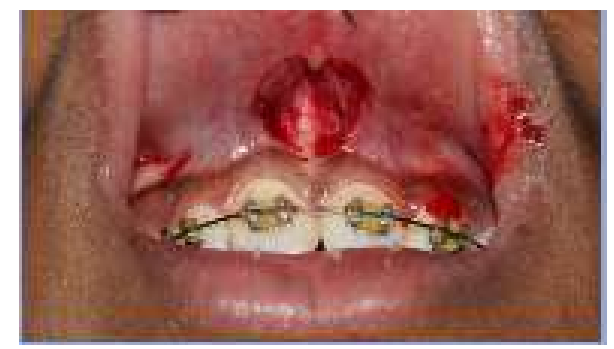

Fig 2: Intraoperative view- Frenectomy

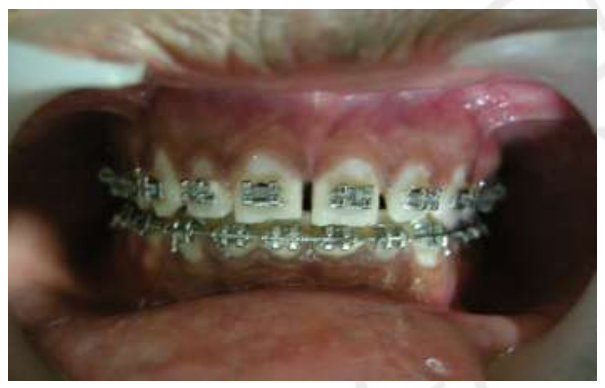

Fig 2: 2 weeks Post-operative view

Electrocautery and lasers are used and also been proposed for frenectomy 4 . Electrocautery probe is used due to the effectiveness of treatment, for the safety of the procedure, for the mild bleeding and for the absence of post-operative complications. The electrocautery has been associated with some complications such as the risk of an explosion when combustible gases are used, like burns, involvement with pacemakers and surgical smoke. The new improvements introduced in electrosurgical techniques have eliminated the complications reported like the Argon Beam Coagulation $(\mathrm{ABC})^{5}$.

In recent times, in frenectomy procedure, the use of $\mathrm{CO}_{2}$ laser has been reported as a safe and an effective option. The advantages of $\mathrm{CO}_{2}$ laser in frenectomy are shorter duration of surgery, simple procedure, less pain, absence of post-operative infection and no scar ${ }^{4}$. In labial frenectomies, for infants the application of diode and Er:YAG lasers ${ }^{6}$ are used and in adults and prepubescent Er,Cr:YSGG lasers ${ }^{7}$ are used.

\section{CROWN LENGTHENING:}

The esthetic teeth and gingival relationship includes some established and recommended characteristics such as:

Tooth proportionality

Contacts, connectors, and embrasures

Gingival characteristics

\section{TOOTH PROPORTIONALITY:}

The golden proportion of the ideal maxillary incisors should be approximately $80 \%$ of width when compared with height. In some cases the ideal proportion can vary based on the ideal height of the tooth. The corresponding solutions to the tooth height - width problem are all variant, including bonding, to increase the length of the tooth,awaiting completion of passive eruption or the periodontal crown lengthening.

\section{CONTACTS, CONNECTORS , AND EMBRASURES:}

The tooth contact, connectors and embrasures are the real significance for planning the treatment of smile. The exact place where the anterior teeth touch is called as contacts (Interdental contacts). The connector is where the incisor and canine "appear" to touch. There are certain appropriate ratios for connectors; the connector between the central incisors is about $50 \%$ of tooth height; the ratio for central and lateral incisor connector is of about $40 \%$ of central incisor tooth height; and the ratio for lateral incisor and canine connector is of about $30 \%$ of the central incisor tooth height. The embrasures appear to be smaller between central incisors and as they progress posteriorly in dentition they grow larger.

\section{GINGIVAL CHARACTERISTICS:}

The gingival shape and gingival contour are the two most important concepts for the final esthetic outcome of the orthodontic patients. Gingival shape refers to the curvature of gingival margin of the tooth. The gingival margin of the tooth is determined by the cementoenamel junction and the osseous crest. According to the accreditation criteria for the American academy of dentistry, "The shape of the 
gingiva in mandibular incisors and the maxillary laterals shows a symmetrical half - oval or half circular shape and the maxillary centrals and canines shows a gingival shape which is more elliptical". Gingival zenith plays pivotal role in the anterior esthetics and is the most apical point of the gingival tissue. It should be distal to the longitudinal axis of the maxillary central incisors and canines. The most apical point of the gingival tissue in maxillary lateral incisors and mandibular incisors should correspond with their longitudinal axis 8 .

\section{TREATMENT:}

Gingival overgrowth is often seen postorthodontic treatment. This results in dysmmetry in the gingival characteristics with an unesthetic appearance. This discrepancy can be corrected by crown lengthening by gingivectomy to get proper tooth proportionality and gingival characteristics and maintaining the biologic width of the teeth postorthodontically. (Fig 4, Fig 5 and Fig 6)

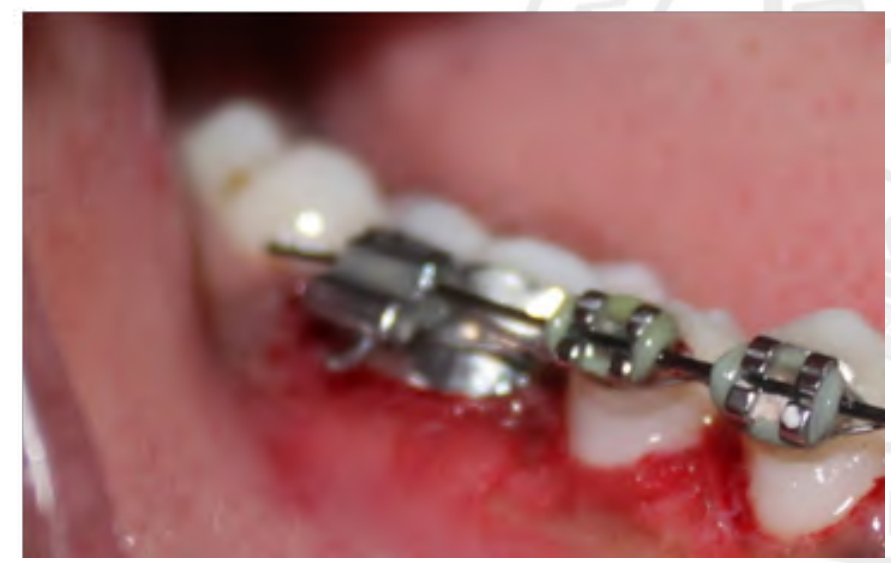

Figure 4: Preoperative View

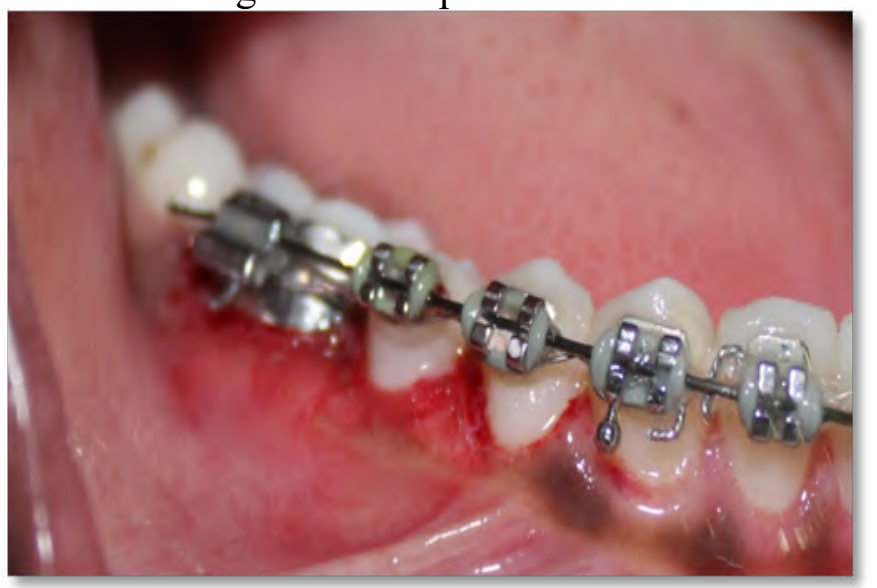

Figure 5: Intraoperative View- Crown Lengthening by Gingivectomy

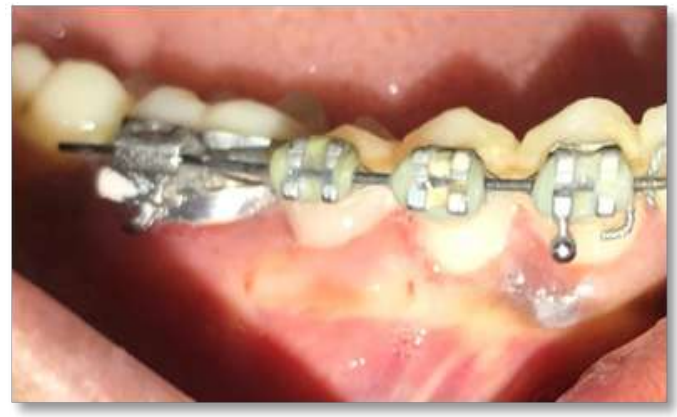

Figure 6: 2 weeks Postoperative View

\section{GINGIVOPLASTY:}

Gingivoplasty is the surgical recontouring of the gingiva during or any post-orthodontic gingival discrepancy in order to achieve a physiologic contour of the gingiva. The attached gingiva surrounding the teeth is reshaped to provide more esthetic and functional contour of the gingiva (Fig 7, Fig 8 and Fig 9).

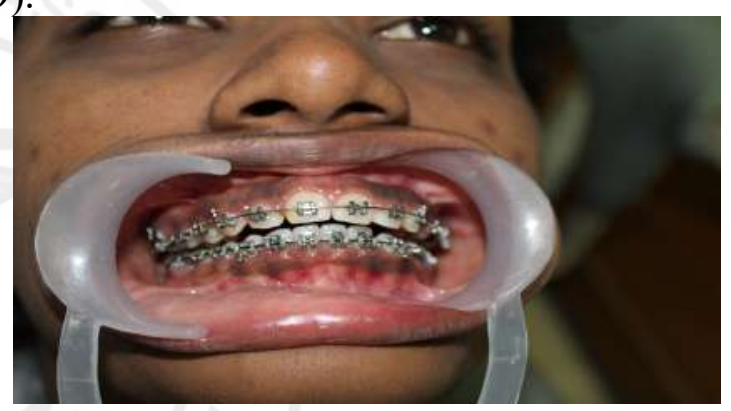

Fig 7: Pre-operative view

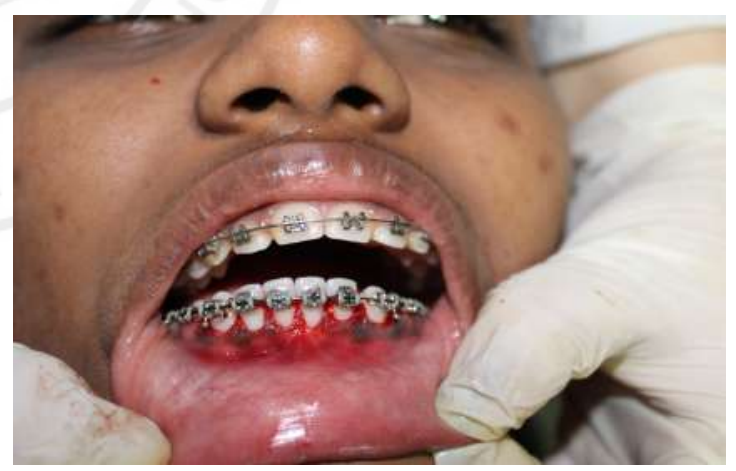

Fig 8: Intraoperative view- Gingivoplasty

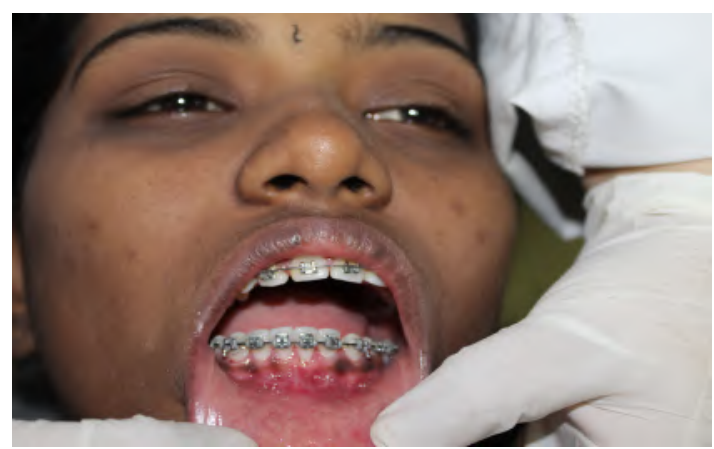

Figure 9: 2 weeks post-operative view 


\section{GINGIVAL RECESSION:}

Gingival recession is the apical shift of the marginal gingiva from its normal position on the crown of the tooth to levels on the root surface beyond the cementoenamel junction and it may affect the labial and lingual or interproximal areas. The etiology is multifactorial in nature, with both predisposing and precipitating factors implicated. The factors to establish the anatomic and morphologic property in the gingival recession are the alveolar bone dehiscence, ectopic tooth eruption, the thin buccal mucosa, crowding and presence of aberrant frenula. The precipitating factors include traumatic and aggressive tooth brushing and piercing. The debate exists in the relationship between the role of orthodontic treatment and the role of gingival recession. The most common risk factor for gingival recession is associated with the movement of teeth outside the alveolar bone though others have found no such league.

Good, long term (5years) results have been announced with coronally advanced flaps and connective tissue grafts. Few alternative methods include the laterally positioned flap with or without connective tissue graft and the free gingival graft is used in single and multiple gingival recessions. In this gingival recession management, graft is removed from the palate and the necrosis of the graft causes high morbidity. The patients are re- educated about the importance of brushing technique and other cleaning aids such as toothpicks, floss and interdental tooth brushes are also highlighted.

To reduce the risk of gingival recession and to increase the importance of orthodontic treatment, the orthodontist must be conscious of and should take account of considering not just of the crowns, but also the cortical plates and roots are also more important.

Thus, to minimize the risk of treatment procedures in gingival recession include the following:

- To maintain proper and a good oral hygiene throughout the orthodontic treatment and identify potential risk factors.

- Eliminate potential causes of recession (piercing, smoking, traumatic tooth-brushing)

- Avoid uncontrolled dento-alveolar expansion and maintain arch form

- Customize bonding and mechanics.

- Modify tooth anatomy whenever indicated.

- Consider segment arch mechanics.

- The space should be created before using it and the created space should be used wisely.

- Consider atypical extractions using analysis. e.g. compromised teeth.

- Avoid fidget because it may cause periodontal problems.

- Treatment should be done early ("interceptive procedure and treatment in mixed dentition").

- The patient should be re-educated about their oral hygiene technique after the end of the treatment.

\section{TREATMENT:}

Gingival recession can also occur postorthodontically as a result of orthodontic forces acting on the teeth. This can be corrected by root coverage procedures using pedicle flaps, free soft tissue grafts, connective tissue grafts after the orthodontic treatment is completed.(Fig 10 and Fig

\section{1)}

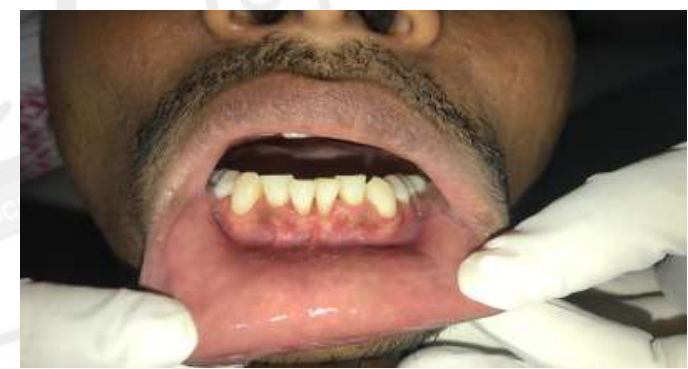

Figure 10: Preoperative View

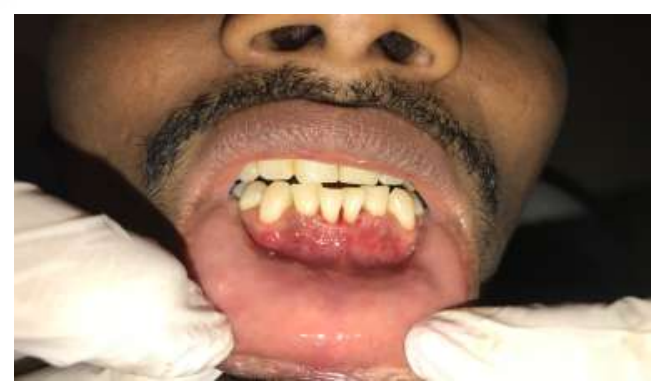

Figure 11: Postoperative View

\section{WILCKODONTICS:}

The nature of orthodontic tooth movement needs was revolutionized by a novel treatment method combining selective alveolar decortication, alveolar augmentation and orthodontic treatment called Periodontally Accelerated Osteogenic Orthodontic Procedure which is patented by "Wilckodontics" 
based on the emerging concepts of Wilckobrothers ${ }^{9}$. Wilckodontics is performed during the week following bracketing and archwire activation. Facial and lingual selective alveolar decortications are performed utilizing circumscribing corticotomy cuts and intra-marrow penetrations. In some cases, the activated bone and exposed root surfaces are covered with the bone graft material (allograft/xenograft) (Fig 7). This treatment procedure provides advantage of reduced time period for orthodontic treatment in adult patients together with reduced need for extraction and elimination of aggressive intervention of rapid maxillary expansion.
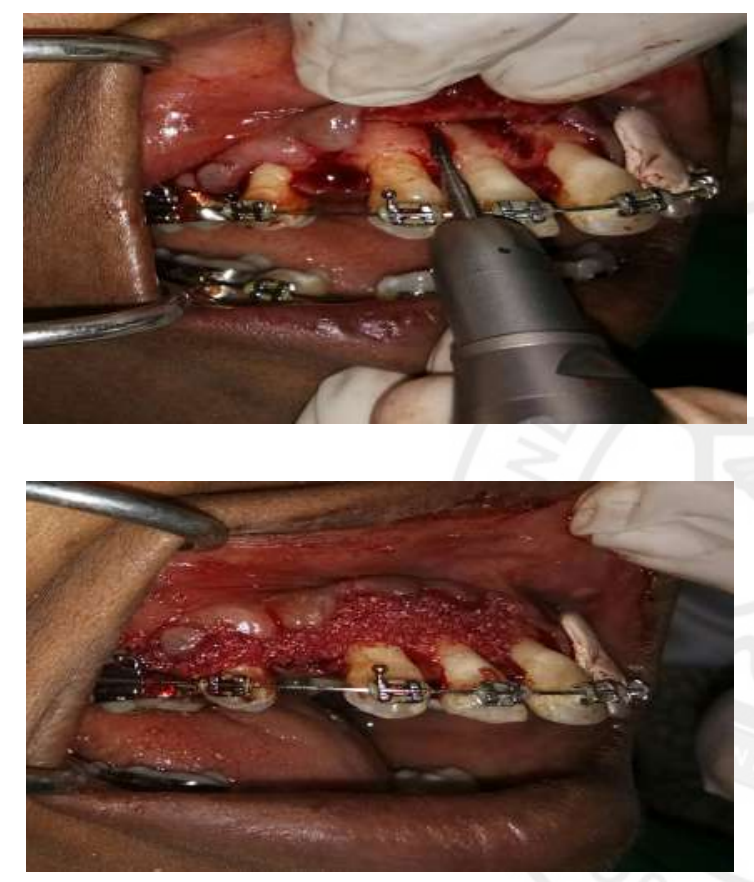

Figure 12: Selective decortication, alveolar augmentation and orthodontic tooth movement

\section{FORCED TOOTH ERUPTION:}

Forced tooth eruption is the orthodontic tooth moment in a coronal direction from the alveolar socket into the oral cavity by applying light continuous orthodontic force. Several factors such as root length, root form, level of fracture of tooth, relative importance of tooth, esthetics and endodontic and periodontal prognosis of the tooth to be erupted are taken into consideration. If all these factors are favorable, forced eruption of the fractured root is indicated. After the tooth root has been erupted, it must be stabilized to prevent it from intruding back into the alveolus. The reason for reintrusion is the orientation of the principal fibers of the periodontium. During forced eruption, the periodontal fibers become oriented obliquely and stretched as the root moves coronally. These fibers eventually reorient themselves after about 6 months. Before this occurs, the root can retrude significantly. Therefore, if this type of treatment is performed, an adequate period of stabilization is necessary to avoid significant relapse and retrusion of the root.

\section{FIBEROTOMY:}

A Pericision is an orthodontic surgical procedure carried out to help for minimizing the extent of rotational relapse of teeth.This method was developed by Edwards JG. The main reason for relapse after orthodontic treatment is rebound of the network of elastic supracrestal gingival fibers. When the teeth move to new position, these fibers are stretched and remodelling of these fibers takes a long time. Fiberotomy or pericision involves elimination of the pull of elastic supracrestal gingival fibers by sectioning these fibers. The teeth are held in the corrected position; when the fibers heal, thereby reducing the relapse caused by elasticity of the gingival fibers.

This is a simple painless procedure performed using scalpel to sever the fiber attachment around the tooth. Without damaging the supporting periodontal structures the "Laser CSF" is used. It is an efficient procedure to decrease the relapse after tooth rotation since orthodontically rotated teeth without retainers have more relapse tendency 10 .

\section{CONCLUSION:}

The most widely applied technique now in orthodontic treatment is laser technique and it has proved to have many benefits. Soft tissue lasers can be used to perform all prosthodontic, retentive, esthetic measures in periodontium which includes gingivectomy, frenectomy, fiberotomy and surgical exposures of the tooth with less bleeding and wound contraction and reduced pain. The spirit of interdisciplinary approach between Orthodontic and Periodontic relation always provide the stable and evidence based results in the treatment of orthodontic patients.

\section{FINANCIAL SUPPORT AND SPONSORSHIP:}




\section{CONFLICTS OF INTEREST:}

There are no conflicts of interest

\section{REFERENCES:}

1. Huang WJ, Creath CJ. The midline diastema: a review on its etiology and treatment. Pediatric Dentistry. 1995;17:1719. [PubMed] [Google Scholar]

2. Dibart S, Karima M. Dibart Serge, Karima Mamdouth. Practical Periodontal Plastic Surgery. Germany: Blackwell Munksgaard; Labial frenectomy alone or in combination with a free gingival autograft; p. 53. [Google Scholar]

3. Cunha RF, Silva JZ, Faria MD. A clinical approach of ankyloglossia in babies: a report of two cases. J Clin Pediatr Dent. 2008;32:27782. [PubMed] [Google Scholar]

4. Verco PJW. A case report and a clinical technique: argon beam electrosurgery for the tongue ties and maxillary frenectomies in infants and children. European Archives of Paediatric Dentistry. 2010 Jan; www. findarticles.com, accessed on. [Google Scholar]

5. Kafas P, Stavrianos C, Jerjes W, Upile T, Vourvachis M, Theodoridis M, et al. Upperlip laser frenectomy without infiltrated anaesthesia in a paediatric patient: a case report. Cases Journal. 2009;2:7138.

6. Gontijo I, Navarro RS, Naypek P, Ciamponi AL, Haddad AE. The application of diode and Er:YAG lasers in labial frenectomies in infants. J Dent Child. 2005;72(1):10-5.

7. Olivi G, Chaumanet $\mathrm{G}$, Genovese MD, Beneduce C, Andreana S. The Er,Cr:YSGG laser labial frenectomy: a clinical retrospective evaluation of 156 consecutive cases. Gen Dent. 2010;58:126-33.

8. American Academy of Cosmetic Dentistry. Diagnosis and treatment evaluation in cosmetic dentistry - a guide to accreditation criteria. Madison: American Academy of Cosmetic Dentistry.

9. Hajji SS. The influence of accelerated osteogenic response on mandibular decrowding [thesis] St Louis: St Louis Univ; 2000 .

10. Laser-aided circumferential supracrestal fiberotomy and low-level laser therapy effects on relapse of rotated teeth in beagles.Kim SJ1, Paek JH, Park KH, Kang SG, Park YG. Angle Orthod. 2011 Jul;81(4):738. 